\title{
Informar la Gran Guerra desde un periódico local: el caso de El Correo del Atlántico (1914-1917)
}

\author{
Eugenio QUESADA RIVERA \\ Universidad de Costa Rica \\ equesadar@gmail.com
}

Recibido: 31 de julio de 2013

Aceptado: 10 de septiembre de 2013

\section{Resumen}

El objetivo de este artículo es analizar la forma en la que se informó sobre la Gran Guerra a través de las páginas del Correo del Atlántico. Se tiene la hipótesis de que éste fue un periódico germanófilo y que funcionó como la voz de la colonia alemana en Costa Rica mientras duró el conflicto europeo. Se analizan las fuentes informativas, las temáticas de las noticias, así como también las relaciones que tuvo el impreso con otros órganos de prensa costarricenses en lo relativo a la Gran Guerra.

Palabras clave: Gran Guerra; prensa local; información; periodismo; agencias de noticias.

\section{Informing the Great War from a local newspaper: the case of El Correo del Atlántico (1914-1917)}

\begin{abstract}
This article analyzes how the First World War was depicted through the pages of the costa rican local newspaper El Correo del Atlántico. The main hypothesis argue that this newspaper was germanophile and worked as the voice of the german population in Costa Rica during the european conflict. The informative sources, the themes of the news and the relationship between the newspaper and other costa rican press institutions regarding the Great War were analyzed in order to achieve the objetive of this research.
\end{abstract}

Keywords: Great War; local newspaper; information; journalism; news agency.

\section{Referencia normalizada}

Quesada Rivera, E. (2013) Informar la Gran Guerra desde un periódico local: el caso de El Correo del Atlántico (1914-1917). Historia y Comunicación Social. Vol. 18, págs. 305-321.

Sumario: 1. Introducción. 2. El formato. 3. Las fuentes y los temas de las noticias. 4. La postura germanófila. 5. Relaciones con otros órganos de prensa. 6. Conclusiones. 7. Bibliografía.

\section{Introducción}

La Primera Guerra Mundial, catalogada como una guerra de creencias (Schulze, 1999: 165), fue el primer acontecimiento mediático del siglo XX. Son los periódicos el principal medio de comunicación de la época y el espacio donde esas creencias 
despiertan las más encarnizadas pasiones, que llegan hasta el insulto para defender el bando de preferencia.

Costa Rica se hallaba lejos del escenario de la guerra y permaneció neutral casi hasta el final, pero ello no le impidió tomar partida en el conflicto a través de las páginas de los periódicos que circularon en todo su territorio. Desde el estallido del conflicto, el 28 de junio de 1914, las informaciones referentes a este acontecimiento ocupan buena parte de las planas de los impresos costarricenses.

Se toma como objeto de estudio un impreso que nace y muere en el contexto de la Gran Guerra: El Correo del Atlántico, autodeclarado defensor de los intereses generales de las provincias de Limón y de Cartago y en el que es frecuente encontrar informaciones referentes al conflicto bélico. Se parte del supuesto de que este periódico es de tendencia germanófila y que fue la voz de la colonia alemana en Costa Rica mientras duró la conflagración. El estudio se extiende desde el 23 de noviembre de 1914, día en que el periódico vio la luz, hasta el 29 de setiembre de 1917, cuando se vio obligado a cerrar.

La manera en la que los periódicos informaron la Primera Guerra Mundial ha despertado el interés de investigadores de diversos países. En España destacan los trabajos de Betancor $(2006,2008,2009,2010)$ quien ha investigado ampliamente las implicaciones que la Gran Guerra tuvo en la prensa canaria. En México, de la Parra (1986) comparó los mecanismos informativos de los dos periódicos más importantes: El Universal y El Demócrata, su estudio concluye que detrás de cada impreso se hallan miembros de las colonias de los países en pugna que interfieren en el contenido.

Para el caso centroamericano y en particular el costarricense, Vega (2007, 2009, 2010 y 2012) ha analizado, entre otros aspectos, las fuentes informativas, las relaciones de los impresos con las agencias telegráficas internacionales y, en general, las transformaciones que el periodismo experimentó a raíz de la guerra. Valga señalar que sus trabajos han tomado como objeto los periódicos aliadófilos capitalinos, por lo que el estudio que aquí se expone es novedoso en tanto trata un periódico local, aspecto poco explorado por los investigadores costarricenses.

Las fuentes utilizadas para este análisis han sido todos los ejemplares que circularon de El Correo del Atlántico, así como también los estudios que sobre la prensa durante la Gran Guerra se han elaborado. Se recurre también a algunos ejemplares de los diarios La Información y El Imparcial. Para trabajar estas fuentes se confeccionó una base de datos donde se indica el título de la noticia, la fecha en que se publicó, el número de página donde se encuentra, la fuente de donde procede la información, la ciudad de procedencia (cuando se indica) y el tema central.

El objetivo de este estudio es analizar la forma en la que se informó sobre la Gran Guerra a través de las páginas de El Correo del Atlántico. Adicionalmente, se buscará dar respuesta a las siguientes interrogantes: ¿Cuál es la posición que ocupan este tipo de noticias en el impreso? ¿Cuáles son las fuentes con las que nutren sus noticias? 
¿Cuál es la posición del periódico frente al conflicto? ¿Cuáles son las temáticas más frecuentes en las informaciones? ¿Cuál es la relación de El Correo del Atlántico con otros órganos de prensa costarricenses con respecto a las noticias de la guerra?

\section{EI formato}

El Correo del Atlántico es un semanario de provincia cuyo aspecto es similar al de los principales impresos capitalinos; es un periódico de gran formato a seis columnas y con cuatro páginas (ver Figura 1). La tecnología de la que se dispone en las provincias que funcionan como su sede (Limón primero y Cartago después de marzo de 1915) es insuficiente para su impresión, por lo que debe enviarse a talleres josefinos. Esta situación genera irregularidades en la circulación del periódico, por ejemplo el $1^{\circ}$ de enero de 1915 sus responsables deben excusarse por adelantar la entrega:

Pero como quiera que las imprentas de San José, donde por necesidad del formato tiramos nuestro periódico, no trabajarán, por ser días festivos, en los tres primeros días del presente, hubiéramos tenido necesidad de publicarlo con retraso, lo que no hubiera sido de nuestro agrado ${ }^{1}$.

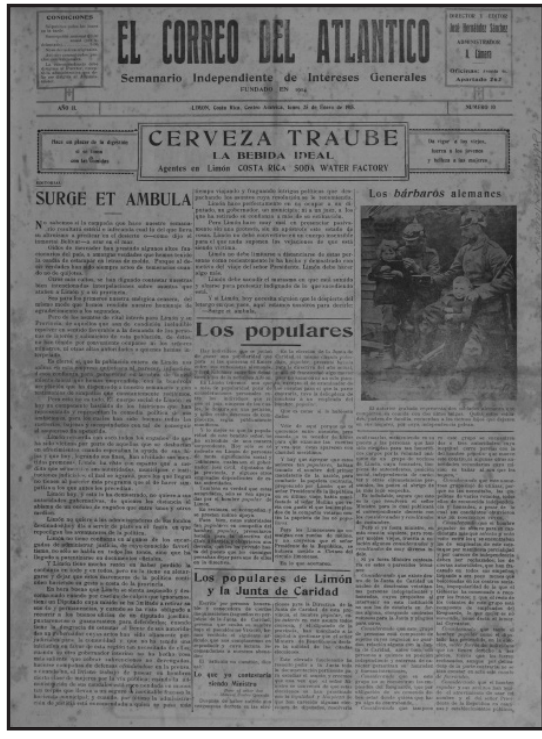

Figura 1. El Correo del Atlántico, 25-01-1915, p. 1

Durante los casi tres años de circulación, $E l$ Correo del Atlántico publicó un total de 1110 notas relacionadas con la Gran Guerra, es decir, un promedio de 6,8 noticias por edición. La cantidad de informaciones fluctuó a lo largo del período en estudio, como se ilustra en el gráfico 1. Durante el primer semestre de 1915 vieron la luz 271 noticias, lo que lo convierte en el periodo con mayor número de informaciones. Por el contrario, el segundo semestre de 1914 es el que cuenta con menor cantidad de noticias publicadas (2), dado que solo circularon seis números y el periódico se encontraba en plena consolidación.

Entre marzo y junio de 1915 se elevó considerablemente la cantidad de informaciones sobre la conflagración europea. Esta situación obedeció al traslado de la sala de redacción de Limón a la ciudad de Cartago, lo que permitió al periódico "disponer de telégrafo, teléfono, etc. y estar por la proximidad a la capital al tanto de los acontecimientos más importantes" (El Correo del Atlántico, 19-03-1915: 1). El traslado se tradujo en una mejora de la sección informativa del impreso. 
A partir del segundo semestre de 1915 se evidencia un descenso en la cantidad de noticias publicadas, situación similar a la reportada por Vega en los periódicos josefinos desde inicios de ese año (2012: 156). A partir de agosto de 1915 El Correo del Atlántico deja de publicar los cables, aerogramas y telegramas que venía recibiendo. Esta situación podría deberse a dos causas: la primera que los costos que generaba recibir la información internacional resultaran demasiado onerosos para un sema-

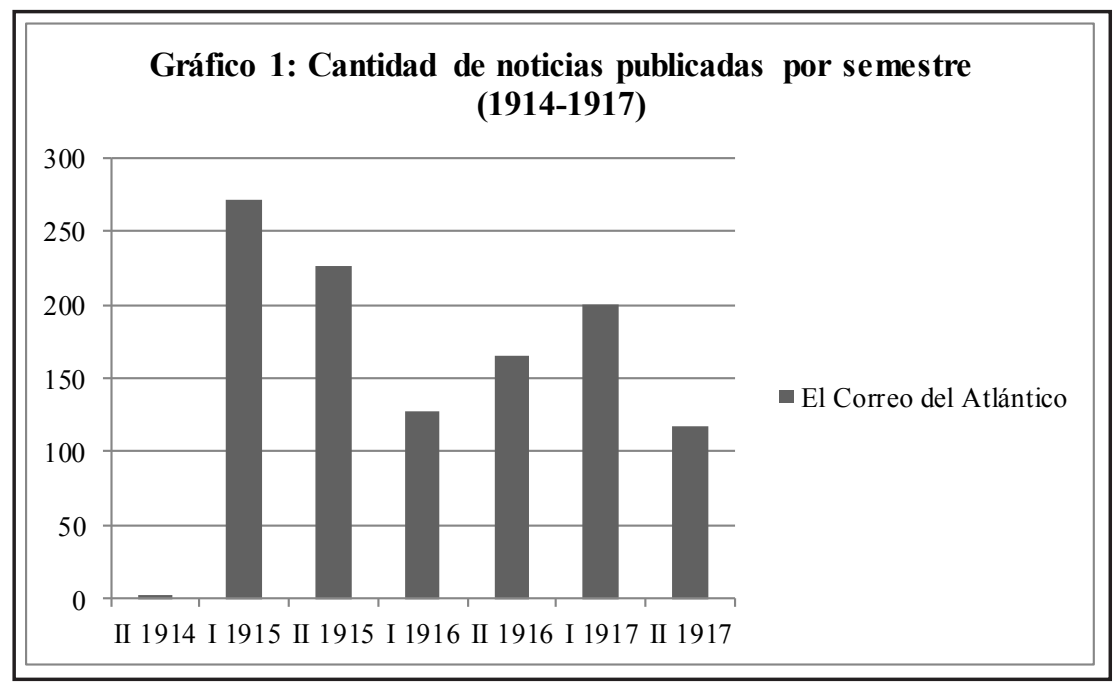

Fuente: Elaboración propia a partir de El Correo del Atlántico, 1914-1917

nario de no muy amplia circulación y la segunda que existiera desde entonces una persecución hacia las publicaciones abiertamente germanófilas.

La persecución a este tipo de publicaciones se concretó después del 23 de mayo de 1918, cuando el gobierno de Federico Tinoco declaró la guerra al imperio alemán. Pocos días después se emitió un reglamento que establecía la pena de sesenta días de arresto o el confinamiento por seis meses a "cualquier habitante del territorio que circule noticias falsas o alarmantes o especies de tendencia germanófila"2. El 29 de junio del mismo año el Ejecutivo emitió un decreto con el que quedaba establecida la censura a las comunicaciones postales y telegráficas provenientes de los países de la Triple Alianza ${ }^{3}$.

El cierre de la imprenta de El Imparcial en 1917, tras un proceso abierto por Federico Tinoco para conocer si dicho taller era propiedad del Estado ${ }^{4}$ acabó con el impreso del mismo nombre y con El Correo del Atlántico, que desde febrero de ese año se daba a la estampa en dicho taller. En efecto, este último periódico pudo mantenerse solamente por dos meses más tras el cierre de la imprenta.

Otro elemento que conduce a sospechar que la persecución de los cables alemanes era un hecho antes de la emisión del Reglamento de Guerra de 1918 lo constituyen 
los comentarios publicados en las páginas de El Correo del Atlántico, por ejemplo el 11 de agosto de 1917 uno de sus responsables se lamentaba de que:

Condenados a no tener otras noticias que las que nos quieren suministrar las compañías anglo sajonas [Reuters y la Prensa Asociada], todas desfavorables a Alemania, no sabríamos de la eficacia terrible del submarino, si de vez en cuando no nos llegasen informaciones verídicas de países neutrales ${ }^{5}$.

El ingreso de los Estados Unidos a la guerra en abril de 1917 suscitó un nuevo interés por el conflicto, lo que se tradujo en un aumento de las noticias difundidas. Además, durante los primeros seis meses de ese año El Correo del Atlántico modificó el formato con el que venía presentando las noticias a sus lectores, haciéndolo más atractivo con la inserción de noticias de última hora precedidas de grandes titulares (Figura 2).

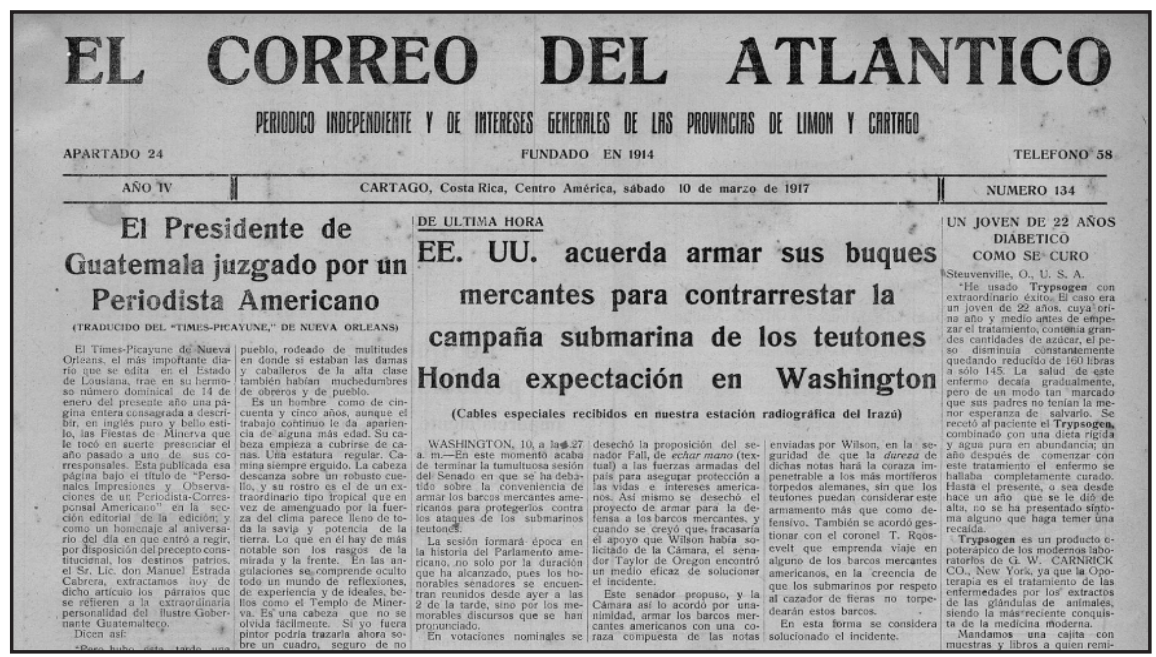

Figura 2. El Correo del Atlántico, 10-03-1917, p. 1

$\mathrm{Al}$ analizar la distribución por el número de página donde se encuentran las noticias (Gráfico 2), resulta evidente que las informaciones referentes al conflicto europeo fueron el material de portada de El Correo del Atlántico. Un 47,12\% del total de las notas analizadas se hallan en la primera página del periódico, lugar reservado para las noticias más importantes, lo cual revela el peso que tuvieron este tipo de informaciones en la Costa Rica de entonces.

En la portada se colocan los cables, aerogramas y telegramas que se reciben en la sala de redacción; luego, al dejar de publicarlos, este espacio es cedido a una serie de secciones fijas que el periódico elabora para comentar las novedades de la Gran Guerra. El resto de las páginas generalmente es usado para la reproducción de textos provenientes de otros periódicos o a la exposición de opiniones. 


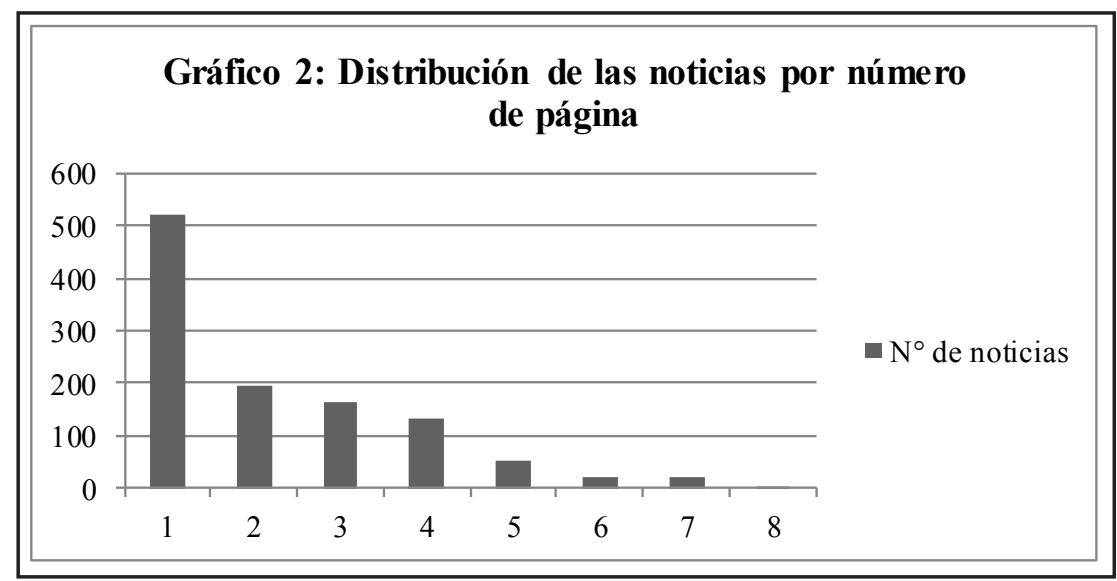

Fuente: Elaboración propia a partir de El Correo del Atlántico, 1914-1917

\section{Las fuentes y los temas de las noticias}

En este apartado se indaga cuáles son las fuentes de las que se nutren las informaciones que presenta El Correo del Atlántico a su público lector, conocerlas permite aproximarse a la forma de operar de la empresa periodística así como también saber las conexiones que ésta tiene. Además, se examinan los principales temas que abordan las noticias, lo cual deja entrever la posición del periódico respecto al conflicto europeo.

El gráfico 3 pone de manifiesto que este periódico recurre a tres fuentes principales: las colaboraciones de redactores pagados por la empresa periodística, los cables y los periódicos internacionales. Sin duda, los cables fueron la fuente más novedosa durante la Gran Guerra, aunque ofrecían desventajas como la llegada tardía de las noticias y las constantes interrupciones del servicio debido a cambios climáticos u otros percances (Vega, 2007: 286).

El Correo del Atlántico no escapó a estas situaciones, de hecho en las ediciones del 6 y 28 de mayo de 1915 tuvieron que comunicar a su público que "a la hora de entrar en prensa el presente número no hemos recibido los cables ordinarios, por cuyo motivo nos hemos privado del placer de darlos a nuestros lectores".

Los cables llegaban en enorme cuantía, ofreciendo un gran acervo de información que los periódicos no siempre podían incluir en sus ediciones. El Correo del Atlántico tenía la desventaja de ser semanario, por lo que contaba con menos espacio para difundir noticias y, además, las hacía llegar con retraso, lo que le dificultaba competir con la prensa diaria. La empresa palió esta necesidad mediante la apertura de una sala de lectura en la que: 
las principales noticias que nos trasmiten el cable y el inalámbrico serán suministradas al público por medio de pizarras en nuestra oficina con algunas horas de anticipación de la llegada de la prensa de San José, que es cuando el público de Cartago acostumbra a recibirlas ${ }^{6}$.

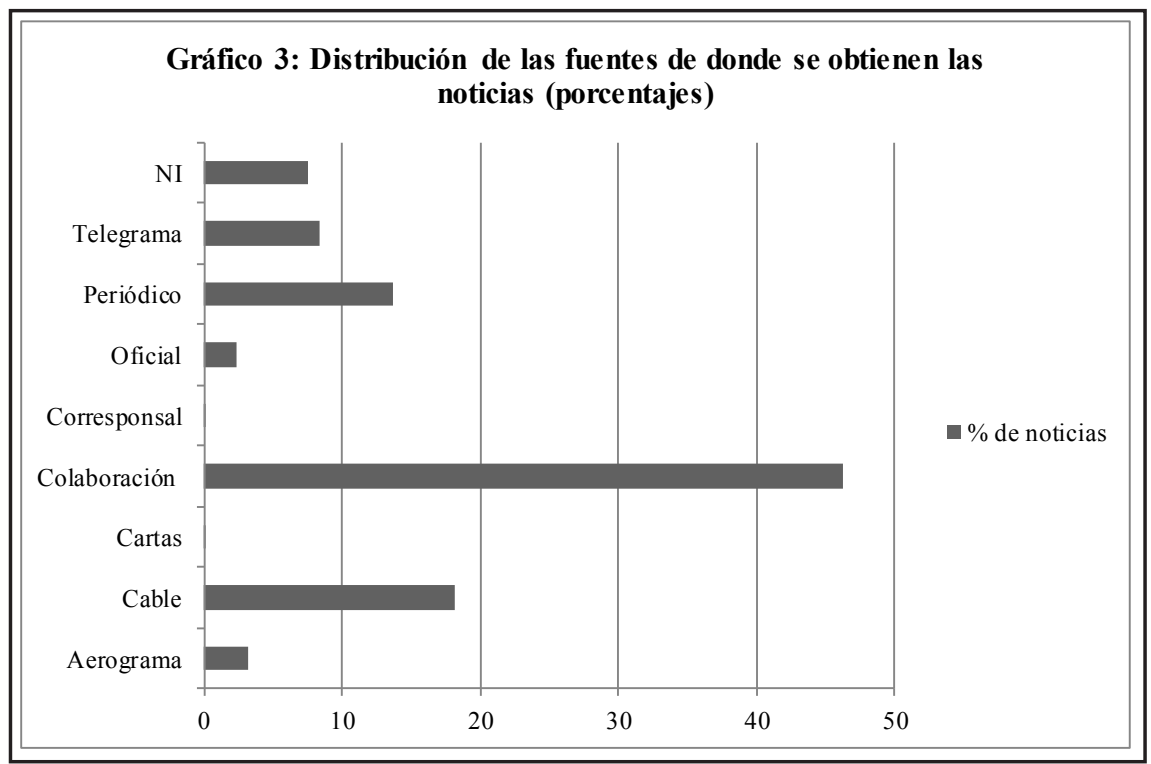

Fuente: Elaboración propia a partir de El Correo del Atlántico, 1914-1917

El Correo del Atlántico recibía al menos dos servicios de cables. Uno de ellos fue el ordinario, que desde fines del XIX funcionaba gracias a un acuerdo entre los gobiernos de Nicaragua y Costa Rica con la Compañía del Cable ubicada en San Juan del Sur ${ }^{7}$ y cuyos mensajes eran repartidos a todos los órganos de prensa costarricenses.

El otro servicio contratado lo diferenciaba de los periódicos aliadófilos propiedad de Clare y Jiménez, que recibían los cables de la Associated Press, presente en América Central desde 1902 tras negociaciones con las agencias de noticias europeas (Paz, 1999: 115). Las informaciones que ofrecía este servicio provenían de Guatemala, es probable que las transmitiera la Transocean, una agencia de noticias alemana fundada en 1915, dependiente del Ministerio de Asuntos Exteriores y a la que se le asignó la propaganda de ultramar (Schulze, 1999: pp. 188-189).

El parecido que estas notas guardan con las publicadas en El Imparcial (ver Figura 3), donde sí se indica la fuente, hace pensar en la posibilidad de que las noticias sean emitidas por los hermanos Nottebohm, miembros de una influyente familia de Hamburgo propietaria de extensas fincas cafetaleras en Guatemala (Wagner, 2001) y que además se dedicó al negocio de la banca.

En cualquier caso, la censura que el gobierno alemán ejerció a través del Kriegspresseamt (oficina de prensa de guerra) fue tan acérrima y el control de la infor- 
mación tan fuerte (Schulze, 1999: pp. 168.169), que es muy probable que todas las informaciones de Alemania siguieran la misma ruta para llegar al país "desde Europa por inalámbrico a la Estación Radiográfica alemana de Sayville... desde allí son transmitidos por cable a Guatemala y se reciben aquí [Costa Rica] por vía telegráfica" (El Imparcial, 12-09-15: 3).

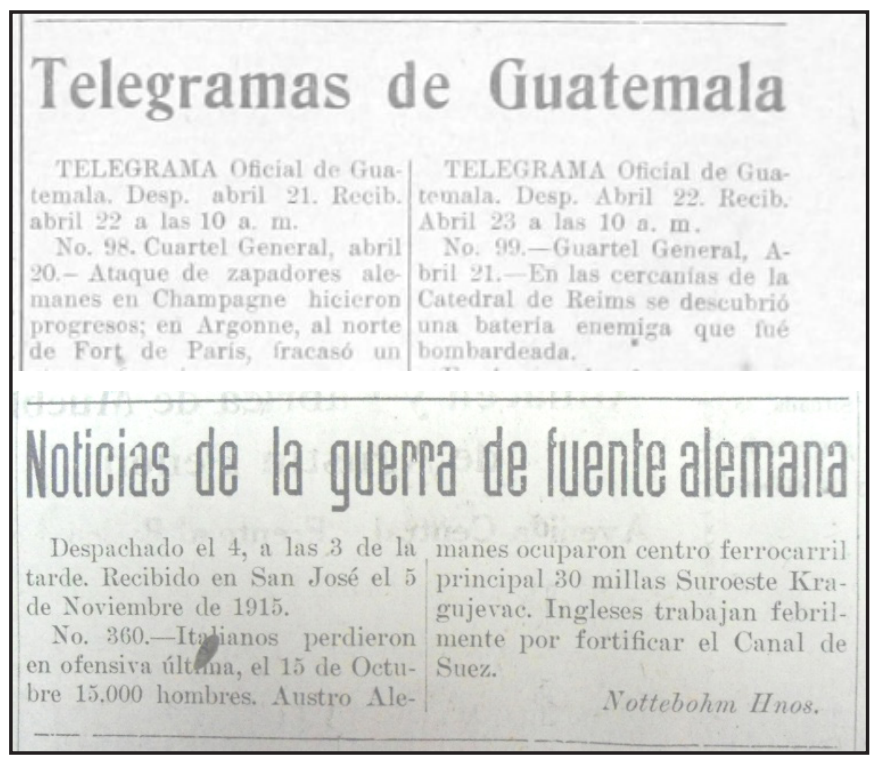

Figura 3. El Correo del Atlántico, 26-04-1915, p. 1 y El Imparcial, 06-11-1915, p.4

Otra fuente de información importante son los periódicos extranjeros, que ofrecen la ventaja de no generar altos costos, pues generalmente gozan de tarifas más baratas dentro de los servicios de correo. De ellos se extraían artículos completos sin problemas, pues en 1916 Costa Rica firmó una Convención internacional de propiedad literaria y artística que establecía que:

cualquier artículo de periódico puede reproducirse por otros, si ello no ha sido expresamente prohibido, debiendo, en todo caso, citarse la fuente de donde aquel se ha tomado.

Las noticias y misceláneas que tienen el carácter de mera prensa informativa, no gozan de la protección de esta Convención ${ }^{8}$.

El Correo del Atlántico había establecido una amplia red de canjes que le permitía recibir impresos de toda Centroamérica, México, Estados Unidos y España. Entre los periódicos que llegaban a su sala de redacción se pueden mencionar: El Eco Alemán de Guatemala, El Cronista de Honduras, El New York American propiedad del célebre Randolph Hearst, la revista Germania de Barcelona y $A B C$ de España. 
Este intercambio era en doble vía: el periódico bajo estudio salió de las fronteras nacionales e incluso sus artículos fueron reproducidos en otros impresos, como $E l$ Eco Alemán de Guatemala y El Eco Universal de Managua (El Correo del Atlántico, 26-02-1916: 3). A esta notable red de canjes contribuyó el hecho de que el director, editor y administrador del periódico, Aureliano Cámara, fuera agente de suscripciones de diversas publicaciones extranjeras como La Hacienda de Nueva York, El Mercurio de Nueva Orleans y El Diario de Panamá (El Imparcial, 16-01-1916: 3).

La fuente de información de mayor uso en El Correo del Atlántico fueron los colaboradores que redactaban para el periódico. Esta fuente acapara casi el $50 \%$ del total de noticias analizadas. Los redactores aparecen en agosto de 1915, justo después de que el impreso deja de publicar los cables, son personas informadas que comentan los cables y las noticias de otros periódicos y aportan su punto de vista.

A lo largo de la vida del impreso aparecen tres columnas con el propósito de informar los pormenores de la Gran Guerra: Notas no rápidas escrita por Un Curioso Lector, La Nota Semanal escrita por Don Crisóstomo y En Broma firmada por Don Crispin. En cada una de ellas se recurre al humor y a la ironía, lamentablemente no se ha podido determinar quiénes están tras esos pseudónimos, pero a partir de una nota en la que Don Crisóstomo contesta a un artículo publicado en La Prensa Libre sobre los españoles, puede deducirse que tras su pluma se halla un miembro de la colonia española:

Ya sabemos los españoles los puntos que calza orador tan insigne como Melquiades Alvarez, que a pesar de su elocuencia cambia de opinión con la misma facilidad que un prójimo de camisa, sobre todo si hay un ministerio en perspectiva ${ }^{9}$.

En cuanto a la distribución temática de las noticias, el gráfico 4 revela la supremacía de tres temas: la denuncia de manipulación informativa por parte de otros periódicos o agencias de noticias, los personajes involucrados en la pugna europea y el avance de los alemanes en los campos de batalla. Llama la atención la disparidad entre las informaciones relativas al avance alemán y el que tuvieron los miembros de la Triple Entente, el primer tema representa un 10,45\% del total, mientras que el segundo alcanza apenas un $3,42 \%$, lo cual deja en evidencia la posición que $E l$ Correo del Atlántico tuvo ante el conflicto.

Las informaciones referentes al avance de los teutones disminuyen a partir de 1917, cuando la guerra da un revés para este bloque, las pocas notas relacionadas con el tema comienzan a ser imprecisas, por ejemplo el 9 de junio de ese año el columnista publica lo siguiente:

¿Qué sucede en Kronstadt? ¿Han tomado los alemanes esta fortaleza, base naval de la escuadra rusa y llave de Petrogrado? ¿O son los rusos que la guarnecían los que se han pronunciado a favor de Alemania? $?^{10}$

Las informaciones referentes a los personajes evidencian la puesta en práctica de enormes campañas de información y propaganda que, planificadas y organizadas desde los Estados a partir de los estudios científicos sobre las colectividades, perse- 


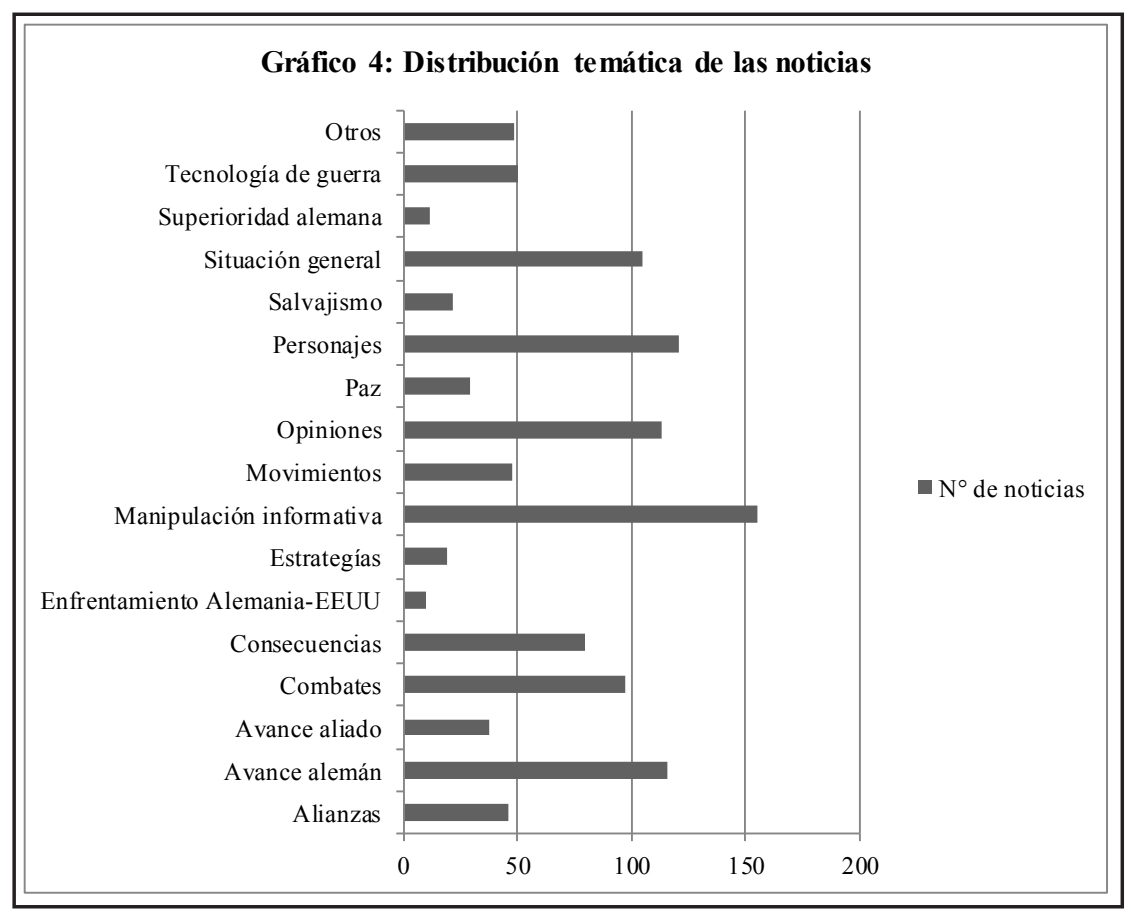

Fuente: Elaboración propia a partir de El Correo del Atlántico, 1914-1917

guían crear una respuesta uniforme: el apoyo de los ciudadanos a uno u otro bloque (Bordería, Laguna y Martínez, 1998: 355). No son raras las notas dedicadas al Kaiser Guillermo II para celebrar su natalicio (El Correo del Atlántico, 29-01-1916: 1 y 27-01-1917: 1), referirse a los cigarros que fumaba (El Correo del Atlántico, 11-121915: 3) o realizar semblanzas de su persona, en una de ellas se le describía como una

figura prestigiosa que llena hoy la más grande página de historia que se ha escrito en los tiempos modernos... de relieve tan saliente para los que antes de esta guerra han estudiado paso a paso el desenvolvimiento comercial, financiero, industrial y agrícola del pueblo alemán, que se puede decir sin exageración alguna que no hay ramo de la manifestación humana, ni campo en que se desarrollen las iniciativas de los espíritus emprendedores, en que no se hayan revelado la cuidadosa atención y la esmerada solicitud con que todos y cada uno de estos problemas han encontrado apoyo y han sido resueltos por el hombre que hoy rige los destinos del pueblo alemán. ${ }^{11}$

\section{La postura germanófila}

Lo expuesto hasta ahora pone de manifiesto la inclinación que muestra El Correo del Atlántico por la Triple Alianza y en particular por los alemanes. Existen publi- 
caciones que no dejan lugar a dudas al respecto, ejemplo de ello es "Las dos caras de la medalla", nota en la que se comparan las informaciones suministradas por dos revistas europeas, una española y otra inglesa, apreciadas de manera muy distinta por el redactor:

en una de ellas campea la manifiesta parcialidad con que defiende la organización y eficacia del ejército de los aliados y la inferioridad del ejército alemán, cosa poco menos que disculpable, por tratarse de una revista inglesa.

La otra que es una revista española completamente imparcial, y que ha censurado cuando lo ha creído conveniente el plan alemán, habla en muy diferente tono de la organización, eficacia y disciplina de ambos ejércitos ${ }^{12}$.

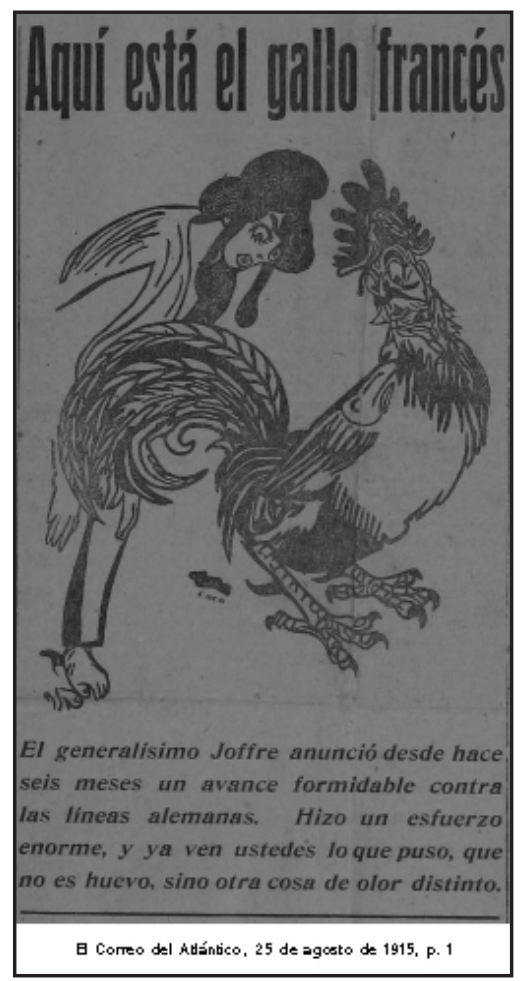

Figura 4

En otra edición, el redactor de Notas Lentas dio por sentado que sus lectores por el solo hecho de leer este impreso eran germanófilos (El Correo del Atlántico, 30-10-1915: 1). Resulta obvio que este periódico se oponía al grupo de los países aliados, una clara muestra de ello es una caricatura del general francés Joseph Joffre (Figura 4) en la que aparece como un gallo defecando -haciendo alusión a uno de los símbolos franceses- $\mathrm{y}$ en la que se hace mofa de sus intentos por avanzar frente al ejército alemán.

En el bando aliado circularon gran cantidad de rumores elevados a la categoría de noticias por parte de la prensa, que relataban las atrocidades cometidas por los alemanes como fueron las historias de soldados que cortaban las manos a los niños, cocían cadáveres para fabricar jabón o crucificaban a los prisioneros de guerra (Bordería, Laguna y Martínez, 1998: 360). Todos estos rumores fueron rebatidos a través de las páginas de El Correo del Atlántico.

El 11 de marzo de 1915 la portada del periódico incluía un artículo titulado "La administración alemana en las provincias del Norte y Este francés" en donde se afirmaba que los soldados alemanes trataban a la población francesa con todas las consideraciones y que "allí donde ponen los pies los soldados tudescos no hay más que orden y buena administración".

La noticia difundida por la agencia Reuters sobre la existencia de una fábrica en Alemania que usaba los cadáveres para la producción de abono y jabón, fue desmentida argumentado que: 
solo una intelectualidad que queda debajo del nivel de un salvaje antropófago puede imaginarse que algún pueblo, aunque sea el menos civilizado, implante o consienta una industria de aquella índole, la que sería imposible ocultar una sola semana $^{13}$.

¿A qué se debe esta defensa acérrima de los intereses de Alemania en un periódico en Costa Rica? Los súbditos del imperio alemán que residen en el país están tras $E l$ Correo del Atlántico como colaboradores, redactores e incluso como anunciantes. Es muy frecuente encontrar la publicidad de Cerveza Traube, de Edgar Knöhr y Cía., del almacén de abarrotes Steinvorth o del azúcar Niehaus, todos propiedad de alemanes. Además, la colonia alemana otorgaba al periódico una subvención mensual dos mil quinientos colones (El Correo del Atlántico, 11-11-1916: 3)

No se trata de un caso aislado, pues en México la colonia germana financiaba a El Demócrata y otros periódicos que simpatizaban con la causa teutona (de la Parra, 1986: 159) y en Las Palmas, Islas Canarias, los alemanes que allí residían tomaron como medio de comunicación al diario La Provincia (Ponce, 1992: 598). No resulta sorprendente entonces que la colonia alemana de Costa Rica proyectara sus ideas a través de las páginas de un periódico.

La colonia alemana de Costa Rica comenzó a gestarse después de la independencia de España, pero a partir de 1871 se vio impulsada por un comercio creciente, producto del nuevo contexto político del imperio alemán (Berth, 2006: 11). Los germanos residentes en suelo costarricense se dedicaron a la producción cafetalera, al cultivo de azúcar, a las actividades bancarias o fungieron como ingenieros o técnicos, lo que les hizo ocupar las posiciones más elevadas de la pirámide social. Destacaron, incluso más que los ingleses, en la actividad política; desempeñándose como diputados, presidentes del Congreso, ministros y diplomáticos (Herrera, 1985: pp. 146-147).

Numéricamente, los alemanes en Costa Rica fueron importantes. El censo de 1892 reportó un total de 342 personas originarias de Alemania, una cantidad muy superior a la de los habitantes provenientes de Inglaterra (246) o de Francia (189) ${ }^{14}$. Para 1927 esta colonia contaba con 685 almas (Berth, 2006: 13). Si la colonia alemana gozaba de tanto poder ¿por qué utilizaba un medio de comunicación marginal? Esta es una pregunta que escapa de los objetivos planteados para este análisis, pero que queda abierta para próximos estudios.

Finalmente, desea añadirse que la colonia alemana no solo utilizó este periódico con el fin de movilizar la opinión pública costarricense a favor del imperio alemán, sino que también fue un canal para comunicar las actividades que realizaba, como la feria del 3 de diciembre de 1916

destinada a colectar fondos que engrosarán las sumas que sirven de sostén al admirable servicio sanitario de la Cruz Roja con que los imperios centrales mitigan el dolor y la situación de los patriotas que en todos los extremos de Europa... ofrendan generosamente su sangre para preservar la independencia y el honor de sus países ${ }^{15}$. 


\section{Relaciones con otros órganos de prensa}

Este último apartado está dedicado a explorar las relaciones que durante la Gran Guerra se tejieron entre la prensa germanófila costarricense -representada por $E l$ Correo del Atlántico - y los diarios josefinos aliadófilos La Información y La Prensa Libre, ambos publicados por la Imprenta Moderna y propiedad de Clare y Jiménez.

Costa Rica, como se mencionó con anterioridad, declaró la guerra a Alemania hasta mayo de 1918, a pocos meses del fin de la conflagración, pero esto no impidió que se desatara un férreo combate en donde los órganos de prensa actuaron como trincheras para los dos bloques en pugna. Si algo caracterizó las relaciones entre la prensa pro-germana y la pro-aliada fue la hostilidad.

El periódico provinciano insultaba constantemente a los periódicos josefinos. Por ejemplo, a raíz de una imprecisión en un artículo publicado en La Prensa Libre relacionado con los submarinos, El Correo del Atlántico reaccionó afirmando que "si se desconoce este extremo [capacidad de los submarinos], entonces es un "ignorante estúpido" que debiera dejar de escribir para evitar lamentables chascos" (24-051915: 5).

No obstante, la pugna más fuerte la mantiene con La Información. A este impreso se le tacha de "periodicucho", pero también se le acusa de publicar informaciones inexactas y de corte amarillista, como lo evidencia una de las notas publicadas en la sección Notas no rápidas:

Los cables de Nueva York dicen que a consecuencia de la escasez de tintes y anilinas, que dicho sea entre paréntesis los aliados no han acertado a fabricar, el papel que en lo sucesivo empleen los periódicos será de un tinte amarillo.

Lo cual dará ocasión para que $L a$ informalidad y sus dos hijastras no tengan que ocultar su color ${ }^{16}$.

\section{La Informalidad y La Inflamación} fueron motes que utilizaron los redactores del periódico local con la intención de ridiculizar las publicaciones que hacía el impreso capitalino. El 10 de octubre de 1915 el autor de la columna Notas no rápidas comenzó a llamar al periódico de Clare como La Inflamación, pues "en los

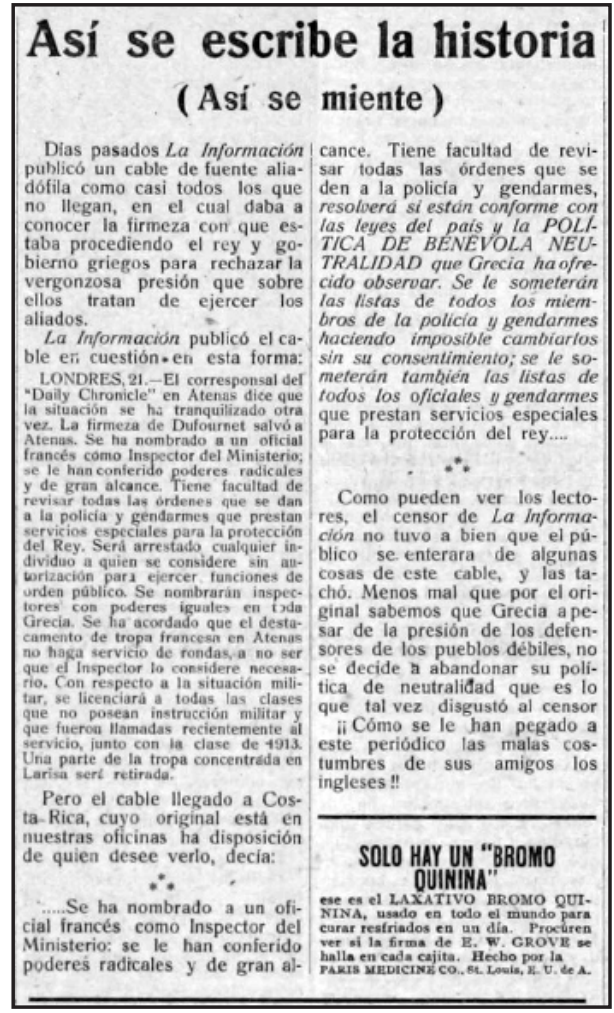

Figura 5 
presentes días aparece inflado, inflado y relleno" (p. 1) a causa de los avances que los aliados habían realizado en Artois, Francia.

Tampoco fueron raras las acusaciones por parte de El Correo del Atlántico de que el diario La Información manipulaba las noticias y ofrecía cables falsos a sus lectores, así lo denunció el columnista en la edición del 22 de julio de 1916:

La Inflamación tiene especial placer en adulterar de vez en cuando cualquier noticia de la guerra. No sé si lo hace por equivocación disculpable, o si lo hace intencionalmente. Lo que sí sucede es que siempre lo hace en perjuicio de la causa teutónica $\mathrm{y}$ en beneficio de la causa aliadófila ${ }^{17}$.

Nuevamente, el 28 de octubre de ese mismo año El Correo del Atlántico acusó al impreso josefino de manipular información, esta vez aportó como evidencia el cable original recibido a través del servicio ordinario de telégrafo (ver Figura 5) contrastado con la publicación hecha por La Información. La evidencia se hizo acompañar de una nota del editor en la que alertaba a los lectores que "el censor de La Información no tuvo a bien que el público se enterara de algunas cosas de este cable, y las tachó".

La pugna entre El Correo del Atlántico y La Información terminó en los tribunales de justicia. En la edición del 5 de agosto de 1916 el periódico financiado por la colonia alemana realizó una publicación en la que se acusaba a Enrique Peyroutet, ciudadano francés y colaborador del diario josefino, de haber estafado a la United Fruit Company (p. 4). La acusación fue una respuesta a un artículo que Peyroutet publicó en La Información y que El Correo del Atlántico consideró ofensivo para los alemanes. Ante tal situación, el periódico capitalino:

para poner fin a esta campaña anónima y artera, para desenmascarar a los verdaderos autores de esa labor constante de difamación, los autores Clare y Peyroutet, acusaron el periódico citado por injuria y calumnia, pidiendo que los autores de los cargos calumniosos probaran sus asertos o fueran condenados conforme lo manda la ley ${ }^{18 .}$

Lamentablemente no ha podido hallarse el expediente que contiene la querella levantada por La Información, pero entre las consecuencias visibles se nota que $E l$ Correo del Atlántico tuvo que empezar a referirse al periódico josefino por su nombre y no como La Informalidad o La Inflamación como hasta entonces lo había venido haciendo.

\section{Conclusiones}

La Gran Guerra efectivamente fue un acontecimiento mediático, pues mantuvo en ascuas a los lectores costarricenses, quienes se mostraban sedientos de noticias, a pesar del retraso con las que muchas veces estas se ofrecían. La prensa costarricense se dividió en dos bandos: mientras La Información y La Prensa Libre fueron las voces de aquellos que apoyaban a la Triple Entente, El Correo del Atlántico se convirtió en el defensor de los intereses de la colonia alemana. 
Al igual que en otros países de América Latina, en Costa Rica las colonias de los países europeos contribuyeron a sostener órganos de prensa. Los extranjeros se agruparon de acuerdo con sus afinidades, así las cosas tras los periódicos josefinos se encontraban los franceses y los ingleses, mientras que tras la publicación local se hallaban las plumas de alemanes y españoles.

La presencia de agencias de noticias de distintas tendencias fue un hecho en Costa Rica. Los periódicos adquirieron los servicios de aquellas que emitían informaciones favorables al bando que apoyaban. La Información y La Prensa Libre recibieron desde inicios del conflicto los servicios de la Associated Press y a partir de 1917 el de la agencia Reuters. Por su parte, El Correo del Atlántico recibía noticias de fuente alemana, ya fuera de la Transocean o de los Hermanos Nottebohm.

La gran cantidad de información que las agencias de noticias enviaban a las salas de redacción costarricenses obligaron a los responsables de los periódicos a idear estrategias para atraer el público y mantenerlo informado, entre ellas estuvieron la colocación de pizarras informativas y la apertura de salas de lectura en los edificios que albergaban las redacciones, puestas en práctica en la capital y en provincia.

La libertad de expresión resultó lesionada durante el transcurso de la Gran Guerra, el gobierno de Federico Tinoco persiguió los periódicos pro-germanos; en 1918 censuró las noticias favorables al papel del imperio alemán en el conflicto europeo y limitó el libre trasiego de información entre Costa Rica y los países de la Triple Alianza. No se descarta que la persecución a las informaciones germanófilas se haya dado desde antes de la llegada de Tinoco al poder.

\section{Bibliografía}

BERTH, C. (2006). “La inmigración alemana en Costa Rica. Migración, crisis y cambios en entrevistas con descendientes alemanes". Ponencia. VIII Congreso Centroamericano de Historia, Antigua, Guatemala

BETANCOR, O. (2006). "La Primera Guerra Mundial a través de las páginas del periódico 'La Prensa'". En: Tebeto: Anuario del Archivo Histórico Insular de Fuerteventura, n 19, Fuerteventura: Cabildo de Fuerteventura, pp. 137-158

--- (2008). "La Primera Guerra Mundial en el diario El Progreso (1905-1932) de Santa Cruz de Tenerife". En: Boletín de la Real Sociedad Económica de Amigos del País de Tenerife $\mathrm{n}^{\circ}$ Extra 1, Tenerife: Real Sociedad Económica de Amigos del País de Tenerife, pp. 349-360

--- (2009). "La postura aliadófila del diario La Prensa durante la Primera Guerra Mundial". En: Anuario de Estudios Atlánticos, n ${ }^{\circ}$, España: Patronato de la Casa de Colón, pp. 343-366

--- (2010). "La faceta periodística de Manuel Bethencourt del Río, en el diario El Progreso de Tenerife, durante la Primera Guerra Mundial". En: Anuario de Estudios Atlánticos n 56, España: Patronato de la Casa de Colón, pp. 199-222 
BORDERÍA, E.; LAGUNA, A. \& MARTÍNEZ, F. (1998). Historia de la comunicación social. Voces, registros y conciencias. Madrid: Síntesis

DE LA PARRA, Y. (1986). "La Primera Guerra Mundial y la prensa mexicana". En: Estudios de Historia Moderna y Contemporánea de México, n ${ }^{\circ} 10$, México: UNAM

HERRERA, E. (1985). "Los inmigrantes y el poder en Costa Rica". En: Revista de Historia $\mathrm{n}^{\circ}$ 11, Heredia, Costa Rica: Universidad Nacional, pp. 131-159

PAZ, M. (1999). "Las agencias de noticas y la comunicación de masas. En: GÓMEZ, M. \& MARIN, E. (ed.) (1999). Historia del Periodismo Universal. Madrid: Síntesis, pp. 101-135

PONCE, J. (1992). "Prensa y germanofilia en Las Palmas durante la Gran Guerra". En: Anuario de Estudios Atlánticos, $n^{\circ} 38$, España: Patronato de la Casa de Colón, pp. 581-602

SCHULZE, I. (1999). “Guerra y comunicación: una relación compleja”. En: GÓMEZ, M. \& MARÍN, E. (ed.) (1999). Historia del Periodismo Universal. Madrid: Síntesis, pp. 137-184

SCHULZE, I. (1999). "La propaganda alemana en la Segunda República Española". En: Historia y Comunicación Social, ${ }^{\circ} 4$, Madrid: Universidad Complutense de Madrid, pp. 183-197

VEGA, P. (2007). "Primicias de la Primera Guerra Mundial en la prensa costarricense (1914)". En: Inter.c.a.mbio, Año 4 n$^{\circ}$ 5, San José: Universidad de Costa Rica, pp. 271-308

--- (2009). “¿Especulación desinformativa? (La Primera Guerra Mundial en los periódicos de Costa Rica y El Salvador)”. En: Mesoamérica, n 51, Guatemala: Plumsock Mesoamerican Studies, pp. 94-122

--- (2010). "La Primera Guerra Mundial desde el prisma de la prensa. La guerra en los periódicos de Centroamérica y Canarias". En: Memoria: Primer Congreso de Historia del Periodismo Canario: El Periodismo y la cohesión territorial del Archipiélago, Tenerife, España

--- (2012). "Guerra, prensa y manipulación informativa. La prensa centroamericana en 1915”. En: Inter.c.a.mbio, Año 9 n 10, San José: Universidad de Costa Rica, pp. $153-179$

--- (2012). "La prensa centroamericana en la encrucijada de la Primera Guerra Mundial". En: Memoria: XI Congreso Latinoamericano de Investigadores de la Comunicación, Montevideo, Uruguay

WAGNER, R. (2001). Historia del café de Guatemala. Bogotá: Villegas Editores 


\section{Notas}

1 El Correo del Atlántico, $\mathrm{n}^{\circ}$ 7, $1^{\circ}$ de enero de 1915, p. 1

2 Oficial (1918). Colección de Leyes y Decretos de Costa Rica. San José, Costa Rica: Tipografía Nacional, p. 351

3 Ibid., p. 471

4 Oficial (1917). Colección de Leyes y Decretos de Costa Rica. San José, Costa Rica: Tipografía Nacional, p. 172

5 El Correo del Atlántico, n 155,11 de agosto de 1917, p. 4

6 El Correo del Atlántico, n 43, 28 de junio de 1915, p. 1

7 Archivo Nacional de Costa Rica (ANCR), Fondo Gobernación, 45659

8 Oficial (1916). Colección de Leyes y Decretos de Costa Rica. San José, Costa Rica: Tipografía Nacional, p. 375

9 El Correo del Atlántico, n 90, 29 de abril de 1916, p. 1

${ }^{10}$ El Correo del Atlántico, $\mathrm{n}^{\circ}$ 147, 09 de junio de 1917, p. 3

${ }^{11}$ El Correo del Atlántico, n 33, 24 de mayo de 1915, p. 5

12 El Correo del Atlántico, n ${ }^{\circ}$ 9, 18 de enero de 1915, p. 2

${ }^{13}$ El Correo del Atlántico, n 150, 30 de junio de 1917, p. 3

${ }^{14}$ Dirección General de Estadística. (1892). Censo General de la República de Costa Rica. San José, Costa Rica: Tipografía Nacional, p. 16

15 El Correo del Atlántico, n 119, 25 de noviembre de 1916, p. 1

${ }^{16}$ El Correo del Atlántico, n ${ }^{\circ}$ 59, 11 de setiembre de 1915, p. 1

17 El Correo del Atlántico, n 102, 22 de julio de 1916, p. 1

${ }^{18}$ La Información, n²761, 10 de noviembre de 1916, p. 2

\section{El autor}

Eugenio Quesada es bachiller en Enseñanza de los Estudios Sociales por la Universidad de Costa Rica y estudiante avanzado del bachillerato en Ciencias de la Comunicación Colectiva con énfasis en Periodismo de la misma institución. Ganador de una beca del programa "Futuros Líderes en las Américas" del gobierno canadiense para realizar una pasantía en la Universidad de Montreal. Es asistente de investigación en el Centro de Investigación en Comunicación (CICOM) de la Universidad de Costa Rica. 